\title{
AVALIAÇÃO DO DESENVOLVIMENTO DE FRANGOS COBB E MESCLADO COLONIAL EM SISTEMAS CONFINADO E SEMI CONFINADO
}

\author{
Marco Antônio de Morais, Eduardo Canepelle², Danni Maisa da Silva³, Divanilde Guerra³, Marciel \\ $\operatorname{Redin}^{3}$
}

\begin{abstract}
RESUMO - Atualmente o Brasil produz carne de frango mais barata e de melhor qualidade devido a utilização de linhagens comercial no sistema confinado. No entanto, uma parcela significativa da população possui apreço pela carne de frango colonial, os quais são criados no sistema semi confinado. O trabalho teve como objetivo avaliar o desenvolvimento, conversão alimentar e peso ao abate dos frangos do tipo Cobb no sistema confinado e dos frangos do tipo Mesclado colonial no sistema semi confinado. Foram utilizados 50 frangos em cada sistema de criação em delineamento experimental inteiramente casualizado com quatro repetições. O experimento foi desenvolvido no período de 4 de abril a 5 de julho de 2016. Foram realizadas pesagens semanais e o controle de consumo de ração através de monitoramentos diários. Ao final do experimento as aves foram pesadas e, posteriormente abatidas. Na fase inicial da criação os frangos Coob e Mesclado apresentaram ganhos de peso semelhantes, já na fase final os frangos Coob apresentaram ganho médio de peso, superior ao Mesclado em 37\%. A conversão alimentar média foi de 2,5 e 1,9 kg de ração consumida para cada kg de peso de frango produzido nas raças do tipo Cobb e Mesclado, respectivamente. Os frangos Coob apresentaram peso médio ao abate superior ao dos frangos Mesclado, mesmo sendo abatidos sete dias antes demonstrando, assim que frangos Coob criados no sistema de confinamento, apresentam maior ganho de peso se comparado aos frangos Mesclado criados no sistema semi confinado. Os frangos Mesclado, em ambas as fases de crescimento, apresentaram melhor conversão alimentar, sendo que este fato torna viável o desenvolvimento da atividade, visto que o maior custo de produção na avicultura de corte se encontra na ração.
\end{abstract}

Palavras chave: conversão alimentar, frango colonial, frangos de corte, sistemas de criação.

\section{EVALUATION OF THE DEVELOPMENT OF COBB AND MESCLADO COLONIAL IN CONFINED AND SEMI-CONFINED SYSTEMS}

\begin{abstract}
Currently Brazil produces the cheapest and best quality chicken meat with commercial lineages in the confined system. However, a significant portion of the population has an appreciation for colonial chicken meat, which are raised in the semi-confined system. The objective of this study was to evaluate the development, feed conversion and weight at the slaughter of the Cobb type chickens in the confined system and of the Mesclado colonial type chickens in the semi-confined system. Fifty chickens were used in each rearing system in a completely randomized experimental design with four replicates. The experiment was carried out from April 4 to July 5, 2016. Weekly weighing and control of feed intake were performed through daily monitoring. At the end of the experiment the chickens were weighed and later slaughtered. In the initial phase of breeding, the Coob and Mesclado showed similar weight gains, and in the final phase the Coob had an average weight gain, higher than the Mixes in 37\%. The average feed conversion was 2.5 and 1.9 $\mathrm{kg}$ of feed consumed for each $\mathrm{kg}$ of chicken weight produced in the Cobb and Mesclado, respectively. Coob
\end{abstract}

\footnotetext{
${ }^{1}$ Professor da Escola Técnica Estadual Celeiro-ETEC. BR 468, Km 87,9 - Bom Progresso/RS. CEP: 98575-000. Contato (55) 3528-6032.E-mail: marco01morais@gmail.com

${ }^{2}$ Acadêmico do Curso de Bacharelado em Agronomia. Universidade Estadual do Rio Grande do Sul - UERGS. Unidade em Três Passos, Rua Cipriano Barata, 211 - Bairro Érico Veríssimo, Três Passos/RS. CEP: 98600-000. Contato (55) 35222895. E-mail: eduardocanepelle@gmail.com

${ }^{3}$ Docentes da UERGS. Unidade em Três Passos, Rua Cipriano Barata, 211 - Bairro Érico Veríssimo - Três Passos/RS. CEP: 98600-000.Contato (55)3522-2895.E-mails: danni-silva@uergs.edu.br; divanildeguerra@yahoo.com.br; marcielredin@gmail.com.br
} 
chickens showed a mean weight at slaughter higher than those of Mesclado, even though they were slaughtered seven days previously, showing that Coob chickens reared in the feedlot system presented greater weight gain when compared to the Mesclado chickens reared in the semi-confined system. The broilers Mesclado in both phases of growth presented better feed conversion, and this fact makes feasible the development of the activity, since the highest production cost of poultry production is found in the feed.

Keywords: broiler chickens, colonial chicken, food conversion, systems of creation.

\section{INTRODUÇÃO}

A avicultura é umas das atividades que mais evoluiu nos últimos anos, devido a eficiência na produtividade em curto espaço de tempo e com baixos custos de produção (Dos Santos \& Galvão, 2016). O Brasil visando o sucesso na avicultura de corte realizou nas últimas duas décadas várias transformações, tais como a utilização de técnicas modernas de criação, o melhoramento genético do rebanho, o controle sanitário e a eficiência de produção dos animais com a melhoria da conversão alimentar, as quais contribuíram de maneira efetiva para que a avicultura brasileira se tornasse mais competitiva no mercado internacional (Lima, 2005). Dessa forma, hoje o Brasil produz o frango mais barato do mundo e de melhor qualidade (Borges, 2009).

Nos últimos anos observa-se que algumas mudanças vêm ocorrendo nos hábitos alimentares da população, dentre elas pode-se destacar que os consumidores passaram a observar o modo que os alimentos são produzidos. Desta forma, muitos consumidores não prezam apenas pela qualidade do produto, mas também pela forma como ele foi produzido. Neste contexto, um importante nicho de mercado a ser explorado é o representado pelos frangos caipiras criados no sistema semi confinado, pois no Brasil existe parcela significativa de consumidores que tem apresso por este tipo de carne (Dos Santos \& Galvão, 2016; Quevedo et al., 2011; Avila et al., 2003), além do sistema de criação, pois este geralmente proporciona melhor bem estar aos animais, se comparado ao sistema confinado. Sendo assim, a criação de aves para produção de carne tipo caipira é um dos segmentos mais promissores da avicultura, tendo em vista que a carne destes frangos se apresenta mais firme e com sabor mais pronunciado (Madeira et al., 2010).

A avicultura colonial mostra-se facilmente praticável na agricultura familiar, visto que necessita de pouca mão-de-obra, tem um retorno financeiro relativamente rápido e funciona como fonte de alimento para a família (Fernandes \& Silva, 2001). Sendo assim, a avicultura colonial no sistema criação semi confinado vem ganhando destaque principalmente entre os agricultores familiares (Medeiros, 2009; Sousa, 2009). Dessa forma, a Região Noroeste do Rio Grande do Sul a qual é caracterizada por grande número de pequenos estabelecimentos rurais (Trennepohl \& Macagnan, 2008), apresenta enorme potencial para desenvolvimento desta atividade.

O frango Mesclado colonial é utilizado na avicultura colonial, pois é um excelente produtor de carne e ovos. Apresenta plumagens coloridas e se adapta facilmente a alimentação natural baseada em pastagens e cereais, atingindo aos 90 dias aproximadamente $3 \mathrm{~kg}$ de peso vivo (Nutriaves, 2018). Já o frango Cobb, como características externas, apresenta plumagem branca, porte baixo e compacto, sendo o mesmo, recomendado para a produção confinada e em altas densidades. Os frangos do tipo Mesclado colonial e Cobb surgiram através de um programa melhoramento genético que garantiu aos mesmos alto desempenho na produção de carne, tonando assim viável a criação destes animais.

Um dos principais problemas enfrentados nas escolas técnicas que possuem curso técnico em agropecuária no RS é a grande evasão escolar. De acordo com Medeiros (2009), uma das formas de combater a evasão escolar das escolas agrícolas é motivar e enriquecer o currículo escolar dos estudantes através do desenvolvimento de alguns programas e projetos, dentre eles, a avicultura colonial. Assim, o desenvolvimento desse tipo de projeto pode contribuir significativamente na construção do conhecimento dos estudantes e reduzir a evasão escolar, além da obtenção de carne para a subsistência dos alunos.

Neste contexto, o presente trabalho teve como objetivo avaliar o desenvolvimento, conversão alimentar e peso ao abate dos frangos do tipo Cobb no sistema confinado e dos frangos do tipo mesclado colonial no sistema semi confinado.

\section{MATERIAL E MÉTODOS}

O experimento foi conduzido no setor de avicultura da Escola Técnica Estadual Celeiro - ETEC, a qual está 
localizada no município de Bom Progresso, situado a Noroeste do Estado do Rio Grande do Sul. Foram utilizados 100 pintos de corte em dois sistemas de criação, confinado e semi confinado para as raças Coob e Mesclado colonial, respectivamente. O experimento foi desenvolvido no período de 4 de abril a 5 de julho de 2016.

As aves foram alojadas, em um galpão de alvenaria coberto com telhas de fibrocimento, com $33,4 \mathrm{~m}^{2}$, pé direito de $2,80 \mathrm{~m}$, possuindo tela de malha metálica, cortina plástica, lanternim e piso de concreto, o qual foi coberto com maravalha para formação da cama das aves. Internamente o galpão foi dividido ao meio formando dois boxes de $16,7 \mathrm{~m}^{2}$ cada. Para a condução do experimento foram alojados pintos de um dia para ambas as raças, Cobb e Mesclado colonial, os quais foram separados em dois lotes com 50 unidades cada, sendo um lote da raça tipo Cobb e um lote da raça tipo Mesclado colonial. Os pintos utilizados no experimento foram vacinados no incubatório contra doenças de Marek e bouba aviária. Os pintos foram alojados em seus boxes sem separação por sexo, ou seja, machos e fêmeas foram mantidos conjuntamente no mesmo espaço.

No momento da chegada dos pintos, às instalações já se encontravam preparadas e com os equipamentos necessários instalados, como: círculo de proteção, bebedouros e comedouros de alimentação, campânulas com lâmpadas incandescentes (150 Watts) para aquecimento das aves, sendo utilizado uma campanula para cada box, durante os sete primeiros dias. Durante os dez dias iniciais utilizou-se comedouros tubulares e bebedouros infantis do tipo sifão, sendo dois equipamentos de cada tipo por box, para fornecimento de ração e água aos pintos. A partir do décimo dia até o momento do abate das aves, a ração passou a ser fornecida em comedouros tubulares para aves adultas e água em bebedouros do tipo pendular, sendo utilizando um equipamento de cada tipo por box. Diariamente, estes equipamentos eram inspecionados e limpos para garantir funcionamento adequado dos mesmos e fornecimento de água e ração de qualidade aos animais. Ração e água foram fornecidas à vontade para as aves durante todo o período de criação, em ambos os sistemas de criação. A água fornecida aos animais era potável, ou seja, limpa, fresca e isenta de microrganismos.

O período de criação das aves foi dividido em três fases seguindo recomendações de Avila et al.,
(2006): fase inicial (1-35), crescimento (36-65) e final (66-84) dias de idade. As aves foram alimentadas com rações comerciais produzidas pela COTRICAMPO Cooperativa Tritícola Mista Campo Novo, fornecidas nas seguintes fases de criação: Fase inicial, foi fornecida ração tipo 1 , do $1^{\circ}$ ao $35^{\circ}$ dia de idade, nas fases de crescimento e final, foi fornecida ração tipo 2 , do $36^{\circ}$ dia ao final do experimento. Na tabela 1 podem ser observados os níveis de garantia presente nas rações de acordo com as informações do fabricante.

Os frangos da raça Cobb foram criados no sistema confinado, ou seja, desde seu alojamento até o abate permanecerem no mesmo box que possuía $16,7 \mathrm{~m}^{2}$, perfazendo assim 2,9 aves por $\mathrm{m}^{2}$. Já a raça de frango do tipo Mesclado colonial foi criada no sistema semi confinado, seguindo a metodologia descrita por Figueiredo et al., (2001). No sistema semi confinado foram alojas 2,9 aves por $\mathrm{m}^{2}$ no galinheiro e 1,68 ave por $\mathrm{m}^{2}$ nos piquetes. Os frangos contavam com área externa de $453,4 \mathrm{~m}^{2}$, a qual foi dividida em cinco piquetes de $84 \mathrm{~m}^{2}$ cada um, sendo que os mesmos estavam cercados com arame tipo tela trançada com 1,20 de altura. Os piquetes possuíam pastagem formada de grama Tifton 85 (Cynodon spp.). Dessa forma, era realizado rodizio semanal das aves nos piquetes. Além da ração e água que era fornecida dentro da instalação, os frangos recebiam como alimentação alternativa nos piquetes as cascas de pão que eram oriundas do refeitório da escola, resíduos de culturas olerícolas, raspas de mandioca e pedaços de cana de açúcar. Os frangos permaneciam durante o dia todo no piquete e eram recolhidos somente a noite. Ressalta-se que em ambos os sistemas de criação a ração era fornecida à vontade, ou seja, sempre existia ração nos cochos de alimentação.

Tabela 1 - Níveis de garantia presentes nas rações utilizadas na alimentação das aves no experimento

\begin{tabular}{lrr}
\hline \multicolumn{1}{c}{ Níveis de garantia } & Ração 1 & \multicolumn{1}{c}{ Ração 2 } \\
\hline Cálcio (Mín.) & $8 \mathrm{mg} / \mathrm{kg}$ & $7,5 \mathrm{mg} / \mathrm{kg}$ \\
Cálcio (Máx.) & $11 \mathrm{~g} / \mathrm{kg}$ & $11 \mathrm{~g} / \mathrm{kg}$ \\
Extrato etéreo (Mín.) & $25 \mathrm{~g} / \mathrm{kg}$ & $25 \mathrm{~g} / \mathrm{kg}$ \\
Fósforo (Mín.) & $5 \mathrm{~g} / \mathrm{kg}$ & $5,5 \mathrm{~g} / \mathrm{kg}$ \\
FDA (Máx.) & $120 \mathrm{~g} / \mathrm{kg}$ & $120 \mathrm{~g} / \mathrm{kg}$ \\
Fibra bruta (Máx.) & $80 \mathrm{~g} / \mathrm{kg}$ & $50 \mathrm{~g} / \mathrm{kg}$ \\
Matéria mineral (Máx.) & $75 \mathrm{~g} / \mathrm{kg}$ & $65 \mathrm{~g} / \mathrm{kg}$ \\
Proteína bruta (Mín.) & $210 \mathrm{~g} / \mathrm{kg}$ & $180 \mathrm{~g} / \mathrm{kg}$ \\
\hline
\end{tabular}


O delineamento utilizado foi o interiamente casualizado, com quatro repetições em dois sistemas de criação (confinado e solteiro). Em cada sistema de criação foram avaliados oito frangos, os quais foram indentificados desde o início do exprimento. Cada dois frangos avaliados foram consideradas como uma repetição do tratamento (sistema de criação), totalizando oito frangos para cada sistema de criação.

Semanalmente, as aves e a ração consumida foram pesadas, para determinação do ganho de peso das aves e da conversão alimentar. Para determinar o ganho de peso, foi realizada a pesagem semanal das duas aves de cada repetição, e após realizada a média do peso dos frangos em cada tratamento. Os mesmos frangos utilizados para a determinação do ganho de peso semanal também foram utilizados para a determinação do peso médio vivo no momento do abate e para a determinação do rendimento de carcaça (peso da ave limpa, sem pés, cabeça, pescoço e vísceras comestíveis). Já a conversão alimentar foi calculada pela razão entre o total de ração consumida e o ganho de peso no período e corrigida pelo peso das aves mortas. A conversão alimentar das aves foi expressa de acordo com sua fase de crescimento, inicial e final, sendo utilizado no cálculo somente o consumo de ração inicial e final pelas aves.

O abate dos frangos da raça Cobb foi realizado aos 77 dias, sendo assim, foram realizadas 11 pesagens deste lote de frangos. Já os frangos da raça Mesclado colonial foram abatidos aos 85 dias, pois para ser considerado frango colonial pela legislação brasileira as aves têm que ter no mínimo 85 dias, sendo assim, os animais desse lote passaram por 12 pesagens. Os frangos permaneceram em jejum por um período de 8 horas antes do abate e, posteriormente aqueles frangos que foram utilizados como repetição foram pesados para a determinação do peso vivo dos mesmos, e em seguida abatidos seguindo metodologia de MADEIRA et al. (2010). Para a determinação de redimento (ave limpa) seguiu-se os mesmos procedimentos utilizados por MADEIRA et al. (2010). Os resultados obtidos foram submetidos à análise de variância e as médias dos tratamentos comparadas pelo teste de Tukey a 5\%.

\section{RESULTADOS E DISCUSSÃO}

O experimento foi constituído de dois lotes de frangos cada um com 50 animais, no entanto, ao final do período de criação restaram apenas 47 frangos da raça Cobb e 29 da raça Mesclado colonial, respectivamente. A taxa de mortalidade da raça Cobb foi de $6 \%$ devido a morte de três frangos na fase inicial de criação. Essa taxa de mortalidade corrobora com a encontrada, por exemplo, no trabalho de Lima (2005), que também com a raça Coob no sistema confinado verificou uma taxa de mortalidade de 5,32\%. Já para a raça Mesclado colonial a mortalidade foi de $42 \%$. A alta mortalidade dos frangos é atribuída a ruptura de uma mangueira de água do bebedouro na segunda semana de condução do experimento. Devido a isso, todo o box onde estavam alojados os frangos da raça Mesclado colonial foi inundado, o que aliado a baixa temperatura do ar, pode ter ocasionando a morte de onze frangos. Outro fator que contribuiu para que ao final do experimento restassem apenas 29 aves da raça Mesclado colonial foi o ataque de raposas na sétima semana de condução, onde foram mortos dez frangos.

Como resultados do trabalho, na fase inicial de desenvolvimento, que compreendeu até a quinta semana não foram observadas grandes diferenças no ganho de pesos dos frangos do tipo Cobb e Mesclado colonial, como pode-se observar na Figura 1.

Tal resultado pode estar associado ao sistema de criação, pois tanto os frangos do tipo Cobb e Mesclado colonial foram criados no sistema confinado até os 28 dias de vida. No entanto, a partir da quinta semana, os frangos tipo Mesclado colonial passaram para o sistema semi confinado, sendo que a partir de então começaram á ser observadas diferenças expressivas no ganho de peso dos frangos, pois ao final quinta semana a média de ganho de peso dos frangos Cobb foi de 0,996 kg por ave, enquanto que as dos frangos Mesclados no mesmo período foi de $0,658 \mathrm{~kg}$ por ave, ou seja 51\% inferior. Vários autores já concluíram que o sistema de criação afeta o ganho de peso diário ou semanal. Lima (2005) encontrou maior ganho de peso diário nos frangos do tipo Coob que foram criados no sistema confinado, sendo que frangos tipo colonial criados no sistema semi confinado apresentaram menor ganho de peso diário. Hellmeister Filho et al. (2003) também constataram diminuição de $6,74 \%$ no ganho de peso médio diário dos frangos linhagem Caipirinha quando criados no sistema semi intensivo. Segundo os autores citados, as aves criadas neste sistema têm um maior dispêndio de energia durante o período de pastoreio ou de permanência no pasto, se comparada com aves criadas no sistema confinado. Madeira et 


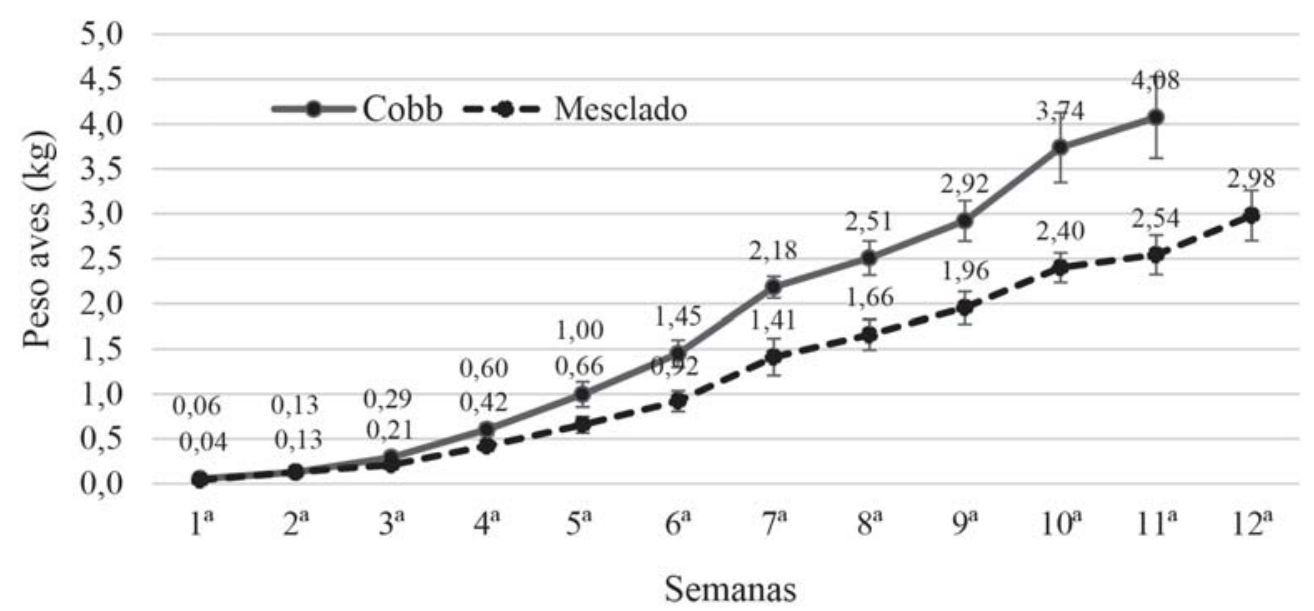

Figura 1 - Ganho de peso das aves do tipo Cobb e Mesclado colonial conduzidas em sistema confinado e semi confinado, respectivamente. As barras verticais representam o desvio padrão das médias.

al. (2010) observaram que os frangos criados no sistema semi confinado, por possuir acesso aos piquetes, desenvolveram maior atividade física, e isto resultou em maior gasto de energia, e consequentemente, estas aves apresentaram menor peso corporal e menor porcentagem de gordura abdominal quando comparados a aves criadas no sistema confinado.

No entanto, Takahashi et al. (2006) concluíram que em todos os períodos estudados (1-28; 29-63; 6484 dias), os ganhos de peso obtidos nos sistemas de criação confinado e semi confinado foram muito semelhantes, ou seja, segundo os autores as quatro linhagens de frangos (Ross, Paraíso Pedrês, Pescoço Pelado e Caipirinha) não tiveram seus ganhos de peso influenciado pelos sistemas de criação. Outro fator que pode ter contribuído para que os frangos tipo Coob obtivessem um maior ganho de peso a partir da quinta semana é o fato dessas aves serem melhoradas geneticamente para apresentar uma eficiência alimentar maior nas primeiras semanas de criação. Segundo Madeira et al. (2010), as linhagens comerciais, como no caso a raça Coob, são resultantes de intenso programa de melhoramento genético que busca garantir aves mais vorazes e que ganham mais peso que aves de linhagens coloniais. Isso ocorre, segundo Takahashi et al. (2006), devido as aves de linhagens comerciais precisarem ser melhoradas para alcançar sua máxima eficiência alimentar até 49 dias de idade, ou seja, nas primeiras semanas de criação, visto que seu tempo de criação normalmente é inferior ao das linhagens coloniais. Segundo estes autores, as linhagens de frango com maior ganho de peso são aquelas que apresentaram maior consumo de ração, sendo assim, justifica-se por que os frangos do tipo Coob apresentaram maior ganho de peso, pois estes consumiram maior quantidade de ração quando comparado aos frangos do tipo Mesclado colonial. Portanto, observa-se que as linhagens de frango de corte colonial, em geral, apresentam menor consumo de ração que as linhagens de frango comercial, com isso, verifica-se maior eficiência alimentar nos frangos de linhagens coloniais.

Os frangos da raça Coob apresentaram um ganho médio de peso por ave de 4,075 kg com 77 dias de vida, ou seja, com 11 semanas; já nós frangos da linhagem Mesclado colonial o peso médio obtido por ave foi 2,981 kg aos 84 dias, ou seja, quando possuíam 12 semanas. Portanto, fica evidente que houve uma diferença no ganho de peso da raça Cobb, sendo superior em relação aos frangos tipo Mesclado colonial no término do lote em 1,094 kg (37\%), mesmo as que aves da raça Cobb tenham sido avaliadas uma semana antes. Este resultado corrobora com os encontrados por Lima (2005), em que as aves da raça Coob criadas no sistema confinado, apresentaram 0,485 kg superior de peso médio por ave ao final do lote, quando comparado aos frangos do tipo colonial que foram criados no sistema semi confinado. Ressalta-se que Lima (2005) avaliou os frangos da raça Cobb até 45 dias de vida e os frangos colonial até os 80 dias de vida, dessa forma, os frangos Cobb foram avaliados 35 dias antes que os frangos 
coloniais, mesmo assim apresentaram maior peso médio por ave ao término do lote. Segundo Figueiredo et al. (2000), os frangos coloniais Embrapa 41, tendem a apresentar maior peso vivo quando são criados no sistema confinado, sendo que o peso vivo esperado aos 84 dias de vida é $2,728 \mathrm{~kg}$ no sistema confinado e 2,255 kg no sistema semi confinado, demonstrando assim que além da linhagem utilizada o sistema de criação também pode influenciar no peso final dos frangos.

Em relação a conversão alimentar dos frangos os dados obtidos no presente estudo na fase inicial e final de criação podem ser observados na Figura 2.

A conversão alimentar dos referidos lotes na fase inicial foi de 2,4 kg de ração consumida para cada kg de peso de frango produzido na raça Cobb e 1,6 kg de ração consumida para cada kg de peso produzido na raça Mesclado colonial. Os resultados demonstram que houve diferença entre frangos da raça Coob e Mesclado colonial para conversão alimentar no período inicial, sendo que os frangos Mesclados apresentaram melhor conversão alimentar se comparados as aves Cobb. No entanto, este resultado difere dos encontrados por Lima (2005), em que frangos Coob criados no sistema confinado apresentaram melhor conversão alimentar quando comparado a frangos coloniais criados no sistema semi confinado. Madeira et al. (2010) também verificaram que frangos de corte comercial da raça Ross apresentaram melhor conversão alimentar quando comprado a outras

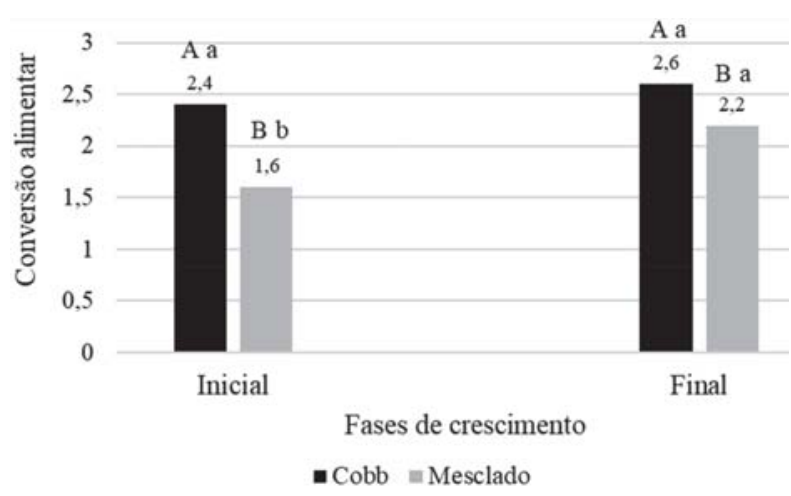

Figura 2 - Conversão alimentar das aves do tipo Cobb e Mesclado colonial conduzidas em sistema confinado e semi confinado, respectivamente. Médias seguidas da mesma letra maiúscula e minúsculas não diferem estatisticamente nas fases e entre as fases de crescimento, respectivamente (Tukey, 5\%). linhagens de frangos coloniais (Máster Griss, Label Rouge e Vermelhão Pesado). Os frangos da raça Coob apresentaram maior consumo de ração na fase inicial. Segundo Santos et al. (2005), isto ocorre devido à alta demanda de nutrientes que é exigido durante as primeiras semanas, afim de garantir que o potencial de ganho de peso da linhagem seja alcançado. Dessa forma, observou-se que a quantidade de ração consumida influencia diretamente na conversão alimentar das linhagens, pois Hellmeister Filho et al. (2003) verificaram que as aves Label Rouge apresentaram maior consumo de ração e estas também apresentaram os menores resultados para conversão alimentar. Segundo estes autores, as aves Pescoço Pelado de Piracicaba que consumiram menor quantidade de ração foram as que apresentaram a melhor conversão alimentar. Verificouse, que os frangos tipo Mesclado colonial na fase inicial apresentaram conversão alimentar de 1,61 sendo que resultado está de acordo com os obtidos por Santos et al. (2005), em que frangos coloniais das linhagens Paraiso Pedrês e Isa Label apresentaram conversão alimentar na fase inicial de 1,62 e 1,64 respectivamente. Figueiredo et al. (2000), ao analisarem os frangos coloniais Embrapa 41, verificaram que mesmo na fase inicial (até 35 dias) apresentaram conversão alimentar de 1,72 quando criados no sistema semi confinado e de 2,20 no sistema de confinamento. Figueiredo (2001) verificou que frangos coloniais Embrapa 41 criados no sistema semi confinado apresentaram conversão alimentar de 2,29 aos 35 dias. Santos et al. (2016) observaram que frangos Mesclados criados com acesso aos piquetes na fase inicial (até 35 dias) apresentaram conversão alimentar de 2,36. Sendo assim, estes resultados são similares aos encontrados no presente estudo com frangos Mesclado colonial criados no sistema semi confinado.

Ao analisar a Figura 2, fica evidente que em ambas as fases de crescimento os frangos Coob apresentaram pior conversão alimentar, se comparado aos frangos tipo Mesclado colonial. No entanto, verificou-se que na fase final ambas as raças de frango apresentaram conversão alimentar estatisticamente igual (Figura 2). Segundo Santos et al. (2005), com o avanço da idade dos frangos, estes tendem a diminuir as diferenças na conversão alimentar entre as linhagens, sendo que isto foi observado no estudo de Takahashi (2003), que avaliou quatro linhagens de frango colonial (Paraíso Pedrês, Pescoço Pelado e Caipirinha) e uma comercial (Coob), e verificou que na fase final de criação as mesmas 
apresentaram igual conversão alimentar. Neste sentido, Takahashi et al. (2006) relatam que as linhagens de frango do tipo colonial tendem a apresentar conversão alimentar semelhante à dos frangos de corte comercial a partir dos 64 dias de idade, uma vez que as aves comerciais são geneticamente melhoradas para alcançar sua máxima eficiência alimentar até 49 dias de idade.

Na fase final de criação a conversão alimentar foi de 2,6 kg de ração consumida para cada kg de peso produzido na raça Cobb e 2,2 kg de ração consumida para cada kg de peso produzido na raça tipo Mesclado colonial. A conversão alimentar encontrada nos frangos da raça Cobb na fase final de criação está de acordo com os resultados obtidos por outros autores como, por exemplo, Santos et al. (2005), que verificaram conversão alimentar média de 2,7 na fase final de criação.

Já as aves do tipo Mesclado colonial na fase final apresentaram conversão alimentar média de 2,20, sendo este resultado semelhante ao encontrado por outros autores para linhagens coloniais, como Avila et al. (2006), que observaram que frangos coloniais da linhagem Embrapa 41 aos 84 dias de vida apresentaram conversão alimentar média de 2,74 quando alimentados com ração com $20 \%$ de proteína. Takahashi (2003) constatou conversão alimentar média dos frangos de corte das linhagens coloniais Paraíso Pedrês, Pescoço Pelado e Caipirinha, aos 84 dias de vida de 2,76, 2,61 e 2,71 respectivamente. Dos Santos \& Galvão (2016) por sua vez verificaram que a conversão alimentar média dos frangos Mesclado colonial no período final da criação foi de 2,61. No entanto, outros autores encontraram valores superiores de conversão alimentar na fase final, como Figueiredo (2001), que afirma que a conversão alimentar média dos frangos coloniais Embrapa 41 aos 84 dias de vida foi de 3,12 quando criados no sistema semi confinado. Madeira et al. (2010), analisando três linhagens de frango colonial Máster Griss, Label Rouge e Vermelhão Pesado, verificaram que a converção alimentar média das aves aos 84 dias de vida foi de 3,10, 3,06 e 3,09, respectivamente. Dessa forma, constata-se que pode ocorrer diferenças de acordo com a linhagem colonial utilizada. A composição da ração utilizada também pode influenciar na conversão alimentar, pois Avila et al. (2003) estudaram três sistemas de alimentação com diferentes concentrações de energia metabolizável e proteína bruta em frangos de uma linhagem colonial, e concluíram que cada sistema de alimentação apresentou valores diferentes de conversão alimentar.
Outro fator que pode afetar a conversão alimentar dos frangos é o fato de serem alimentados nos piquetes, pois no referido experimento, além de ração oferecida dentro da instalação e da grama nos piquetes, também eram fornecidos aos frangos cascas de pão, raspas de mandioca e restos de vegetais (hortaliças). Esse aspecto pode ter contribuído para que os mesmos consumissem menor quantidade de ração, e consequentemente, reduzissem a conversão alimentar, pois a grande maioria dos estudos com linhagens coloniais que são criadas no sistema semi confinado somente oferece como alimentação aos animais ração e vegetação que existem nos piquetes.

Em relação ao peso dos animais no abate, os resultados obtidos mostram que o peso médio vivo por ave da raça Cobb foi de $3,840 \mathrm{~kg}$, enquanto que o peso médio limpo, incluindo a cabeça, pescoço e pés, foi de 3,129 kg. Nesse sentido, o rendimento de carcaça do referido lote foi de $81,44 \%$. O peso médio vivo por ave na raça Mesclado colonial foi de 3,153 $\mathrm{kg}$, enquanto que o peso médio limpo obtido foi de $2,253 \mathrm{~kg}$ e o rendimento de carcaça do referido lote foi de 74,64\%. Lima (2005) também verificou aos 45 dias que os frangos da raça Cobb apresentaram maior peso médio vivo, quando comparado aos frangos coloniais, sendo que o peso médio das aves no momento do abate foi de 2,586 kg e 2,100 kg, respectivamente. Desta forma, no estudo de Lima (2005) os frangos da raça Cobb apresentaram menor peso médio vivo no momento do abate, sendo $1,254 \mathrm{~kg}$ menor, quando comparado aos resultados obtidos neste trabalho.

Constata-se que os frangos de corte de linhagens coloniais tendem a apresentar menor peso vivo ao final, quando estes estão sendo comparados com frangos de corte comercial. Segundo Varoli Júnior et al. (2000), isto ocorre pelo fato das linhagens de frango colonial, apresentarem em geral, o consumo de ração inferior ao das aves comerciais, sendo que isto comprova que as linhagens coloniais têm menor voracidade que as selecionadas para maior velocidade de crescimento e eficiência alimentar. Segundo Santos et al. (2005), os frangos de corte comercial possuem potencial genético que garante o seu crescimento mais acelerado em relação às linhagens caipira. Dessa forma, segundo Vieira \& Moran Júnior (1998), o frango de corte moderno é selecionado para crescimento e, portanto, para consumir grandes quantidades de alimento e como consequência, depositar gordura muito rapidamente e em grandes 
quantidades, o que pode ser uma característica não desejada na carne dos frangos. No entanto, o peso vivo médio obtido nos frangos Mesclado colonial foi superior ao encontrado em outros estudos. Avila et al. (2006), que estudaram diferentes níveis de proteína na ração, verificaram que frangos coloniais apresentaram aos 84 dias de vida peso médio vivo de 2,644 kg e 2,712 kg quando alimentados com rações com teores de proteína de $20 \%$ e $22 \%$ respectivamente, sendo criados em sistema semi confinado. Figueiredo et al. (2001) ressaltam que o peso médio vivo esperado dos frangos coloniais aos 84 dias de vida é de 2,555 kg quando criados no sistema semi confinado. Lima (2005) verificou média de peso vivo dos frangos coloniais (Label Rouge) aos 80 dias de idade de 2,100 kg no sistema semi confinado. Os resultados de Takahashi (2003) demonstram que frangos coloniais da linhagem Paraíso Pedrês aos 84 dias de vida apresentaram peso médio por ave de 3,145 kg criados no sistema semi confinado. Assim, a média do peso vivo dos frangos Mesclado colonial, aliado ao rendimento de carcaça encontrada no presente estudo é muito similar à verificada em outros trabalhos e também está de acordo com dados médios da linhagem, pois segundo ficha técnica da Nutriaves (2018), os frangos do tipo Mesclado colonial tendem a apresentar peso médio vivo de $3,023 \mathrm{~kg}$ até a $13^{\mathrm{a}}$ semana.

Ao final do experimento, é possível inferir que a produção de frangos coloniais é viável, principalmente para pequenos produtores familiares, pois não são necessárias instalações modernas de alto investimento financeiro. Os frangos coloniais podem ter sua alimentação complementada com restos de vegetais, como raspas de mandioca, folhas de verduras, entre outros, e assim, contribuir para o menor consumo final de ração, e consequentemente aumento na margem de lucro. Em adição, a carne dos frangos coloniais apresenta preço superior de venda, sendo que este é um dos principais atrativos para que muitos produtores tenham interesse nessa atividade.

No Brasil existe parcela significativa de consumidores que possuem apreço pelo frango colonial, pois estes possuem características sensoriais diferenciadas das aves criadas em confinamento comercial, como: carne mais escura e firme, sabor acentuado e menor teor de gordura na carcaça (Avila et al., 2003; Takahashi et al., 2006). Segundo Vercoe et al. (2000), os consumidores desejam uma carne com atributos diferenciados, isto é, carne oriunda de animais que foram criados, tratados e abatidos em sistemas que promovam o seu bem-estar, e que sejam ambientalmente corretos. Neste contexto, Takahashi et al. (2006) relatam que é crescente o interesse dos consumidores por carnes com características alternativas, as quais são obtidas mediante produção de aves com desenvolvimento lento e criadas com acesso a piquete, ou seja, no sistema semi confinado, sendo que estas aves são conhecidas como frangos caipiras (região sudoeste), capoeira (região norte) e coloniais (região sul). Do Santos \& Galvão (2016) afirmam que produção de frangos coloniais representa um importante nicho de mercado a ser explorado pelos agricultores familiares, pois existem consumidores dispostos a pagar mais caro por um produto diferenciado, além de manter o homem no campo, sendo assim, a produção de frangos coloniais é uma atividade que está em plena expansão. Segundo Quevedo et al. (2011), este mercado cresce em torno de 5 a 10\% anualmente, com previsão de crescimento maior para os próximos anos devido as exigências cada vez maiores em prol do bem-estar animal.

A produção de frangos coloniais nas escolas agrícolas permite aos estudantes vivenciarem na prática o processo de criação dos frangos, contribuindo assim, de forma efetiva na formação dos estudantes, pois os mesmos são colocados frente à desafios que futuramente poderão enfrentar quando exercerem a profissão de técnico em agropecuária. Medeiros (2009) ressalta que um dos objetivos do curso técnico em agropecuária, é promover a educação dos estudantes através da interdisciplinaridade, a articulação entre teoria e prática. Além disso, a produção de frangos coloniais em escolas agrícolas traz outros benefícios como a economia financeira para a instituição, pois esta não precisaria adquirir no mercado carne de frango.

Vários projetos são desenvolvidos nas escolas agrícolas os quais buscam promover a diversificação da renda dos produtores rurais no campo. Segundo Sobral (2005), a maior parte dos alunos que frequentam as escolas agrícolas são filhos de pequenos e médios produtores. Desta forma, o desenvolvimento de projetos nessa temática, pode despertar o interesse dos estudantes por esta atividade, e assim, promover a permanência destes jovens na propriedade rural, pois a produção de frangos coloniais pode servir como fonte alternativa de renda, com a melhoria das condições de vida no campo. Assim, a produção própria de frangos do tipo Mesclado colonial é uma alternativa alimentar, dessa 
maneira, podendo ser utilizado como fonte de suprimento de alimento das famílias rurais ou na alimentação escolar, e os excedentes poderiam ser comercializados, ampliando a fonte de renda dos produtores rurais.

\section{CONCLUSÕES}

Os frangos da raça Cobb apresentam peso médio ao abate superior ao dos frangos do tipo Mesclado colonial, mesmo sendo abatidos sete dias antes, demonstrando, assim que as aves das linhagens comercial no sistema de confinamento, apresentam maior ganho de peso se comparadas aos frangos coloniais criados no sistema semi confinado.

Os frangos do tipo Mesclado colonial apresentam menor peso ao abate, no entanto apresentaram melhor conversão alimentar, sendo que este fato torna viável o desenvolvimento da atividade, visto que o maior custo de produção da avicultura de corte é com ração.

Portanto, a produção de frangos do tipo Mesclado colonial é uma alternativa de renda para o produtor rural, vistos que estes possuem grande disponibilidade de materiais como fonte de alimentação extra aos frangos. Além disso, a produção de frangos do tipo Mesclado colonial pode contribuir na subsistência alimentar tanto do produtor rural, bem como das escolas agrícolas.

\section{LITERATURACITADA}

AVILA, V.S. et al. Alternativas de sistemas de alimentação na criação do frango de corte colonial Embrapa 041.

Concórdia: Embrapa Suínos e Aves, 2003. 3p. (Comunicado Técnico 336).

AVILA V.S. et al. Avaliação de sistemas de produção e nível proteico da dieta do frango de corte colonial Embrapa 041. Concórdia: Embrapa Suínos e Aves, 2006. 4p. (Comunicado Técnico 431).

BORGES J.D. Formação no ensino agrícola: Avaliação de materiais alternativos para cama de aviário na produção de frango de corte: Um projeto de trabalho com estratégia pedagógica. Dissertação (Mestrado em Ciência em educação Agrícola). Seropédica, RJ: UFRRJ, 2009. 63p.
DOS SANTOS, F.F.; GALVÃO, A.K.L. Criação de frangos de linhagem alternativa por concluintes do curso técnico em agropecuária em Manaus, AM. Nexus - Revista de Extensão do IFAM, v.2, n.1, p.31-37, 2016.

FIGUEIREDO, E.A.P. et al. Criação de frangos de corte coloniais Embrapa 041. Concórdia: Embrapa Suínos e Aves, 2001. 2p. (Instrução técnica para o avicultor 21).

FIGUEIREDO, E.A.P. et al. Frango de corte colonial: uma linhagem para agricultura familiar. Concórdia: Embrapa Suínos e Aves, 2000. 8p. (Folder/Folheto/Cartilha).

FERNANDES, C.M.; SILVA, M. Implantação do sistema alternativo de engorda de aves caipiras através de técnicas de agricultura familiar e associativismo. In: Encontro Técnico Científico de Ciências Exatas e da Terra. Anais... Campo Grande: UFMS, p. 101, 2001.

HELLMEISTER FILHO, P. et al. Efeito de genótipo e do sistema de criação sobre o desempenho de frangos tipo caipira. Revista Brasileira de Zootecnia, v.32, n.6, p.1883-1889, 2003.

HEIER, B.T. et al. Factors associated with mortality in Norwegian broiler flocks.

Preventive Veterinary Medicine, v.53, n.1-2, p.147-158, 2002.

LIMA, A.M.C. Avaliação de dois sistemas de produção de frango de corte: uma visão multidisciplinar. Tese (Doutorado em Engenharia Agrícola). Campinas, SP: Universidade Estadual de Campinas/ Faculdade de Engenharia Agrícola, 2005. 111p.

\section{MADEIRA, L.A. et al. Avaliação do desempenho e do rendimento de carcaça de quatro linhagens de frangos de corte em dois sistemas de criação. Revista Brasileira de Zootecnia, v.39, n.10, p.2214-2221, 2010.}

MEDEIROS, W.M.M. Evasão escolar: o caso do Centro Estadual de Educação Profissional Agrícola Mohamad Ali Hamzé. 2009. Disponível em: < http:// www.diaadiaeducacao.pr.gov.br/portals/pde/ arquivos/1443-8.pdf>. Acesso em: 10 Set. de 2018. 
NUTRiaVes. Pintos de frangas de recreia. 2018. Disponível em: <http:// www.nutriavesdistribuidora.com.br/project/ Mesclado>. Acesso em: 10 Set. de 2018.

QUEVEDO, A.C. et al. Ovos diferenciados. Revista Avisite: Produção AnimalAvicultura, v.5, p.42-44, 2011.

SANTOS, A.L. et al. Estudo do crescimento, desempenho, rendimento de carcaça e qualidade de carne de três linhagens de frango de corte. Revista Brasileira de Zootecnia, v.34, n.5, p.1589-1598, 2005.

\section{SOBRAL, F.J.M. A formação do técnico em agropecuária no contexto da agricultura familiar do oeste catarinense. Tese (Doutorado em Educação). Campinas, SP: Universidade Estadual de Campinas/Faculdade de Educação, 2005. 221p.}

SOUSA, L.C. et al. Avaliação do desempenho zootécnico da avicultura. Revista Brasileira de Agroecologia, v.4, n.2, p.1600-1603, 2009.

TAKAHASHI, S.E. Efeito do sistema de criação sobre o desempenho e qualidade da carne de frangos de corte tipo colonial e industrial. Dissertação (Mestrado em Zootecnia). Botucatu, SP: Universidade Estadual Paulista/Faculdade de medicina veterinária e zootecnia, 2003. 64p.
TAKAHASHI, S.E. et al. Efeito do sistema de criação sobre o desempenho e rendimento de carcaça de frangos de corte tipo colonial. Arquivo Brasileiro de Medicina Veterinária e Zootecnia, v.58, n.4, p. 624632, 2006.

TRENNEPOHL, D.; MACAGNAN, R. Impactos ambientais da dinâmica de desenvolvimento da região noroeste colonial do Rio Grande do Sul. Revista Brasileira de Gestão e Desenvolvimento Regional, v.4, n.1, p.195-220, 2008.

VAROLI JÚNIOR, J.C. et al. Desempenho e qualidade de carcaça de frangos com pescoço pelado. Arquivos Veterinaria, v.16, n.3, p.122-129, 2000.

VERCOE, J.E. et al. Livestock productions systems beyond 2000. Asian-Australian Journal of Animal Sciences, v.13, n.1, p.411-419, 2000.

VIEIRA, S.L. \& MORAN JUNIOR, E.T. Broiler yields using chicks from egg weight extremes and diverse strains. Journal of Applied Poultry Research, v.7, n.4, p.339-346, 1998.

Recebido para publicação em 15/1/2019 e aprovado em 28/03/2019. 